\title{
KARAKTERISTIK FISIK LAHAN DI NAGARI PARU (RIMBO LARANGAN) KABUPATEN SIJUNJUNG
}

\author{
Arie Zella Putra Ulni \\ Program Studi Pendidikan Geografi STKIP PGRI Sumatera Barat \\ ariezella@gmail.com
}

\begin{abstract}
Indonesia is a country that has a tropical climate, tropical climate caused so much rain during the year compared to the dry season. With the tropical climate of Indonesia has a region dominated by forests that are the lungs of the world. One of the existing forests are forests located in the District Lung Nagari Sijunjung Sijunjung or better known by local people with the name Rimbo Prohibition. This study aims to find out about the physical karaksteristik land (slope, landform, hydrology) in Rimbo Prohibition in Nagari Lung District of Sijunjung Sijunjung, knowing how the utilization of land by the community around Rimbo Prohibition. This type of research is descriptive. The results showed that the physical characteristics of the land is very varied Prohibition Rimbo, Rimbo height of Prohibition highly variable, then the slope in Rimbo Laranagn also vary. Landform in Rimbo ban can be divided into three parts, namely the karst hills, alluvial plains and natural levee. Hydrological conditions in the sub-basins of lung depends on the streams flowing from Rimbo Prohibition. Land use specially designated as forests. With Prohibition Rimbo characteristics that vary widely made public memamfaatkan forest products as needed to make Rimbo Prohibition awake d beauty.

Keywords: physical characteristics of the land, the use of Rimbo Prohibition
\end{abstract}

\begin{abstract}
Abstrak
Indonesia merupakan negara yang mempunyai iklim tropis, iklim tropis menyebabkan banyaknya turun hujan di sepanjang tahun dibandingkan dengan musim kemarau. Dengan adanya iklim tropis Indonesia mempunyai banyak wilayah yang didominasi oleh hutan yang merupakan paru-paru dunia. Salah satu hutan yang ada yaitu hutan yang terdapat di Nagari Paru Kecamatan Sijunjung Kabupaten Sijunjung atau yang lebih dikenal oleh masyarakat setempat dengan nama Rimbo Larangan. Penelitian ini bertujuan untuk mengetahui tentang karaksteristik fisik lahan (lereng, bentuk lahan, hidrologi) pada Rimbo Larangan di Nagari Paru Kecamatan Sijunjung Kabupaten Sijunjung, mengetahui bagaimana pemanfaaatan lahan yang dilakukan oleh masyarakat di sekitar Rimbo Larangan. Jenis penelitian yang digunakan adalah deskriptif. Hasil penelitian menunjukkan bahwa karakteristik fisik lahan Rimbo Larangan sangat bervariasi, ketinggian Rimbo Larangan yang sangat bervariasi, maka kemiringan lereng pada Rimbo Laranagn juga bervariasi. Bentuk lahan pada Rimbo Larangan dapat dibedakan menjadi tiga bagian yaitu perbukitan karst, dataran aluvial dan tanggul alam. Kondisi hidrologi pada sub DAS Paru tergantung kepada anak sungai yang mengalir dari Rimbo Larangan. Penggunaan lahan pada khusus diperuntukkan sebagai hutan. Dengan karakteristik Rimbo Larangan yang sangat bervariasi membuat masyarakat memamfaatkan hasil hutan seperlunya agar Rimbo Larangan terjaga keasriannya.
\end{abstract}

\section{PENDAHULUAN}

Indonesia merupakan negara yang kaya akan sumber daya alam, baik sumber daya alam hayati maupun non hayati. Sumber daya alam ini sangat menguntungkan bagi pemerintah maupun masyarakat yang berada disekitarnya. Pemanfaatan sumber daya alam diera pembangunan dipergunakan untuk kesejahteraan masyarakat tentunya memiliki nilai positif sepanjang pemanfaatnya (eksploitasi) dilakukan secara tidak berlebihan dan memperhatikan dampak yang 
ditimbulkannya. Sekarang ini sering kita dengar di berbagai media cetak maupun elektronik eksploitasi sumber daya alam sudah diambang batas kewajaran. Hutan dijarah, sungai penuh limbah dan keaneka ragaman hayati satu-persatu mulai masuk museum atau punah.

Ada juga sumber daya yang dikelola oleh masyarakat biasa yang dilindungi oleh aparat setempat. Namun, mereka tidak memiliki pengetahuan bagaimana cara mengelola sumber daya yang ada tanpa merusaknya. Sehingga banyak menimbulkan dampak seperti masyarakat hanya mengambil hasil alam tanpa memikirkan akibat yang ditimbulkan. Hutan terus ditebang, suhu terus meningkat dan keanekaragaman hayati semakin hilang. Kenaikan suhu mendorong terjadinya peningkatan kebakaran, musim kering yang panjang, Pihak yang merasakan dampak terkuat adalah masyarakat yang mencari penghidupan dari lahan yang sebelumnya hutan atau pertanian kering pada lahan yang semakin miskin dan hanya dari air hujan, dimana kemampuan untuk menyesuaikan diri dengan kegagalan sangat tipis atau bahkan tidak ada.

Hutan merupakan bagian dari lahan terbatas yang terus menciut, dimana konversi lahan pertanian merupakan ancaman terbesar di berbagai negara tropis. Lahan garapan yang berbatasan atau baru dibuka kemungkinan dapat mempertahankan pohon-pohonnya dan memungkinkan regenerasi pohon secara ketidakpastian hak akses ke sumberdaya. Meningkatnya kecenderungan untuk penyerobotan lahan insentif yang merugikan masyarakat umum. Dengan mengetahui karakteristik suatu daerah kita bisa mengetahui bagaimana cara mengelola daerah tersebut sesuai dengan mana mestinya.

Tujuan dilakukannya penelitian ini adalah untuk :

1. Mengetahui karakteristik fisik lahan (lereng, bentuk lahan, hidrologi) pada Rimbo Larangan di Nagari Paru Kecamatan Sijunjung Kabupaten Sijunjung.

2. Mengetahui bagaimana pemanfaatan lahan yang dilakukan oleh masyarakat di sekitar Rimbo Larangan

\section{METODOLOGI}

Penelitian ini dilakukan di Rimbo Larangan yang terdapat di Nagari Paru Kecamatan Sijunjung Kabupaten Sijunjung.Secara astronomis Nagari Paru terletak 
antara 00 32' 30" LS 00 41' 30" LS dan 1010 1' 30"” BT dan 1010 12' 00” BT. Adapun batas-batas wilayah Nagari Paru Kecamatan Sijunjung Kabupaten Sijunjung sebagai berikut :

$\begin{array}{ll}\text { Sebelah Utara } & \text { : Nagari Durian Gadang } \\ \text { Sebelah Selatan } & \text { : Nagari Aia Angek Dan Solok Ambah } \\ \text { Sebelah Timur } & \text { : Nagari Sungai Betung } \\ \text { Sebelah Barat } & \text { : Nagari Muaro }\end{array}$

Nagari Paru merupakan salah satu Nagari dari sembilan Nagari yang terdapat di Kecamatan Sijunjung Kabupaten Sijunjung, dengan luas 74.800 km2. Nagari Paru mempunyai tiga Jorong, yaitu : Jorong Batu Ranjau, Jorong Bukit Buar dan Jorong Kampuang Tarandam. (Kantor Wali Nagari Paru 20014).

Instrumen dalam penelitian merupakan alat dan bahan yang dipergunakan untuk mengumpulkan data di lapangan. Instrumen penelitian meliputi panduan isian untuk menentukan karakteristik lahan di lapangan. Disamping panduan isian dilapangan juga diperlukan dalam penelitian diantaranya sebagai berikut :

\section{Tabel 1 : Alat dan Bahan Penelitian}

\begin{tabular}{|ll|ll|}
\hline \multicolumn{1}{|c|}{ Alat } & \multicolumn{1}{c|}{ Bahan } \\
\hline 1. & Arcview GIS 3.3 & 1. & Peta Geologi Sijunjung \\
2. & Abney Level & 2. & Peta Topografi Sijunjung \\
3. & GPS & 3. & Peta Lereng Sijunjung \\
4. & Alat Tulis & 4. & Peta Bentuk Lahan Sijunjung \\
5. & Kamera & 5. & Peta Penggunaan Lahan Sijunjung \\
& & 6. & Peta Adminstrasi Nagari Paru \\
\hline
\end{tabular}

Penelitian ini menggunakan metode penelitian deskriptif. Pengumpulan data dilakukan melalui observasi, pengolahan peta dan pengukuran di lapangan. Pengamatan dalam kegiatan observasi dan pengukuran dilakukan pada: lereng, bentuk lahan, hidrologi, dan penggunaan lahan serta aktivitas di dalamnya. Pengolahan data peta dilakukan menggunakan program Arc View 3.3, data hasil pengukuran di lapangan ditransformasikan kedalam peta. Untuk menentukan bentuk lahan pada Nagari Paru dilakukan dengan cara sistem overlay antara peta geologi dengan peta lereng.

Berdasarkan uraian di atas maka data yang dibutuhkan unuk pendekatan kuantitatif dalam penelitian ini dapat dikelompokan menjadi dua yaitu data primer yang diperoleh secara lansung dari hasil pengukuran di lapangan dan data sekunder 
yang merupakan data pendukung sebagai sumber acuan dan analisis yang diperoleh dari perpustakaan maupun instansi terkait.

1. Data primer

Data primer ini diperoleh lansung melalui pengukuran dan pengamatan di lapangan. Data primer untuk pendekatan kualitatif adalah hasil wawancara dari informan. Data primer untuk pendekatan kuantitatif yang diamati di lapangan adalah :
a. Kemiringan Lereng dan topografi
b. Bentuk Lahan
c. Hidrologi
d. Penggunaan Lahan

2. Data sekunder

Data sekunder ini merupakan data pendukung sebagai sumber acuan data analisis yang diperoleh dari perpustakaan maupun instansi terkait. Jenis datanya dapat berupa luas lahan, jumlah penduduk, mata pencarian dan lain- lain yang terkait dengan penelitian ini.

\section{PEMBAHASAN}

\section{Karakteristik Fisik Lahan Nagari Paru}

\section{Lereng}

Berdasarkan ketinggian Nagari Paru yang sangat bervariasi, maka kemiringan lereng di Nagari Paru juga bervariasi. Berdasarkan analisis peta topografi yang dianalisis menjadi peta lereng serta hasil pengamatan dan pengukuran dilapangan maka kemiringan lereng Nagari Paru dapat dibedakan atas tiga bagian yaitu : datar (0-8\%), landai (8-15\%) dan agak curam (15-25\%). Sedangkan keadaan lereng Rimbo Larangan di Nagari Paru dibedakan atas landai (8-15\%) dan agak curam (15-25\%). Melihat kondisi lereng yang terdapat di Nagari Paru yang sangat bervariasi, dimulai dengan lereng yang datar sampai kepada lereng yang agak curam.

\section{Bentuk Lahan}

Berdasarkan hasil pengamatan di lapangan dan analisis peta dengan GIS maka bentuk lahan di Nagari Paru dapat dibedakan menjadi tiga bagian yaitu perbukitan karst, dataran aluvial dan tanggul alam. Dataran aluvial terdapat pada daerah yang yang memiliki topografi yang landai, tanggul alam terdapat pada 
daerah yang memiliki topografi yang landai. Sedangkan untuk perbukitan karst terdapat pada daerah yang bertopografi yang curam.

\section{Hidrologi}

Kondisi hidrologi DAS Nagari Paru di pengaruhi oleh iklim dan cuaca serta kondisi penutup lahan disekitar daerah aliran sungai. Iklim di Nagari Paru sama dengan iklim di Sijunjung lainnya, yaitu beriklim tropis dengan suhu udara berkisar antara $26^{\circ} \mathrm{C}-33^{\circ} \mathrm{C}$. Curah hujan rata-rata Nagari Paru adalah $192 \mathrm{~mm} /$ tahun. Curah hujan ini tergolong tinggi, hal ini disebabkan oleh pengaruh iklim tropis.Iklim tropis menjadikan Nagari Paru mempunyai dua musim yaitu musim hujan dan musim kemarau. Sebelum adanya Rimbo Larangan masyarakat Nagari Paru sangat tergantung kepada musim hujan untuk mengolah sawah mereka. Namun, setelah adanya Rimbo Larangan beserta aturan-aturannya, masyarakat tidak lagi mengandalkan air hujan untuk mengairi sawah mereka.

\section{Pemanfaatan Lahan di Sekitar Rimbo Larangan}

Berdasarkan hasil pengamatan dilapangan dan analisis peta dengan GIS, maka penggunaan lahan di Nagari Paru dapat dikelompokkan atas pernukiman, sawah, kebun campuran dan hutan. Permukiman didirikan disepanjang kiri kanan badan jalan, pola permukiman ini dinamakan pola permukiman memanjang .penggunaan lahan yang berupa sawah terletak pada bagian kaki bukit, hal ini bertujuan agar sumber air sawah bisa bertahan dengan cara mengandalkan air yang berasal dari mata air dalam hutan. Jadi masyarakat bisa mengolah sawah mereka kapan pun, sebab mereka tidak hanya mengandalkan air hujan semata untuk sumber air dari sawah mereka.

\section{Karakteristik Fisik Lahan Nagari Paru}

\section{Lereng}

Ketinggian atau elevasi Nagari Paru bisa dikatakan sangat bervariasi yang dimulai dari 100 meter sampai dengan 850 meter dari permukaan laut. Hal ini disebabkan karena Nagari Paru dilalui oleh rangkaian Bukit Barisan. Rangkaian Bukit Barisan inilah yang mempengaruhi ketinggian tempat di Nagari Paru. Karena ketinggian nagari Paru sangat bervariasi, maka kemiringan lereng nagari Paru juga sangat bervariasi. Dengan ketinggian nagari Paru yang dimulai dari 100 meter 
sampai dengan 850 meter mengakibatakan nagari Paru beriklim tropika. Untuk daerah tropika tumbuhan yang bisa tumbuh juga tanaman tropoika juga seperti karet, kelapa dan sebagainya. Untuk nagari Paru masyarakat dominan menanam kebun mereka dengan karet, sebab karet cocok hidup pada daerah mereka.

Hardjowigeno (2011) mengatakan ketinggian wilayah bagi daerah yang beriklim tropis seperti Indonesia, ketinggian wilayah berpengaruh terhadap perubahan iklim, yang kemudian berpengaruh atas pertumbuhan tanaman. Sehubungan dengan sejarah perkembangan pegunungan di Indonesia, ternyata ada beberapa ketinggian pokok, yang masing-masing mempunyai arti penting bagi penggunaan lahan di indonesia.

Berdasarkan peta kemiringan lereng, observasi serta pengukuran lereng di lapangan, maka kemiringan lereng nagai Paru dibedakan atas tiga bagian yaitu datar dengan nilai kemiringan lereng 0-8\%, landai dengan tingkat kemiringan lereng 8$15 \%$ dan agak curam dengan kemiringan lereng 15-25\%. Dengan keiringan lereng yang demikian membuat pengolahan lahan sangat beragam, pada daerah lereng 0$8 \%$ dipergunakan masyarakat sebagai permukiman. Sedangkan untuk daerah yang mempunyai tingkat lereng 8-15\% dipergunakan untuk sawah dan perkebunan. Sedangkan untuk daerah yang memiliki lereng terjal dipergunakan masyarakat sebagai hutan. Hutan inilah yang dijadikan Rimbo Larangan oleh masayarakat Nagari. Rimbo Larangan yang mulanya bertujuan untuk menjaga sumber air sawah secara tidak lansung mencegah terjadi longsor pada hutan ini. Apabila lereng yang terjal terus diolah masyarakat untuk lahan pertanian seperti ladang akan mengakibatkan terjadinya erosi pada permukaan lahan. Erosi yag secara terusmenerus tanpa dilakukan konservasi pada lahan akan menyebabkan terjadinya longsor.

\section{Bentuk Lahan}

Bentuk lahan yang terdapat di Nagari Paru dikelompokkan menjadi tiga bagian yaitu dataran aluvial, tanggul alam dan perbukitan karst. Masing-masing bentuk lahan dipergunakan oleh masyarakat sesuai dengan keadaannya masingmasing. Menurut Suharini (2014) dataran aluvial terbentuk apabila sungai atau aliran yang bermuatan banyak muncul dari bukit atau pegunungan dan mengalir 
menuju ke daerah rendah, maka diendapkanlah aluvium hasil pengikisannya karena terjadi perubahan derajad kemiringan. Aluvium yang diendapkan menyebar dalam bentuk kipas di dataran rendah.

Berdasarkan hasil pengamatan dilapangan, dataran aluvial yang terbentuk di nagari Paru terjadi karena adanya daerah aliran sungai yang mengalir dari punggung-punggung bukit menuju daerah yang memiliki topografi yang lebih rendah. Nagari Paru memiliki iklim yang tropis dan musim hujan sering terjadi, hal inilah yang menyebabkan terbentuknya dataran alvial di Nagari Paru. Air hujan yang masuk ke sungai membawa material-material yang lama ke lamaan akan menumuk pada dataran rendah.

Bentuk lahan yang kedua di Nagari Paru adalah tanggul alam, tanggul alam ini terdapat mengelililngi Nagari Paru. Menurut Suharini (2014) tanggul alam terjadi karena aliran air (arus) yang membawa bahan-bahan hancuran pada kedua tepi sungai. Oleh karena itu arus yang membawa bahan-bahan hancuran tadi berkesempatan untuk diendapkan pada kedua tepi sungai. Proses ini terjadi berulang kali sehingga sungai itu mengalami banjir. Akibatnya adalah bahan-bahan yang diendapkan semakin lama semakin meninggi pada kedua tepi sungai yang berupa tanggul alam secara alami.

Ciri tanggul alam tersebut adalah bahwa lerengnya melandai kearah dataran banjir, sedang lereng ke arah sungai lebih curam. Hal inilah yang terjadi di Nagari Paru, tanggul alamnya terbentuk dari proses aliran air (arus) yang membawa bahan hancuran berupa pasir, tanah dan sebagainya. Akibatnya seringnya terjadi hujan yang deras, maka lama kelamaan material yang dibawa arus sungai tersebut mengendap di tepi sungai dan lama kelamaan menjadi daratan. Hal ini dapat dilihat adanya lereng yang sangat curam di samping kiri kanan sungai.

Bentuk lahan terakhir yang terdapat di Nagari Paru adalah perbukitan karst. Perbukitan karst hanya sedikit, disana ditumbuhi oleh vegetasi penutup lahan seperti kayu gadis, kayu beringin dan tumbuhan yang memiliki akar yang menjalar lainnya. Suharini (2014) mengatakan ditempat yang terdiri dari karst itu terjadi karena proses penghanyutan oleh air danjuga terjadi proses pengikisan secara fisik dan kimia. Selama penghanyutan terjadi korosi, sehingga batuan padat dan 
keraspun akan terbentuk alur-alur ataupun celah-celah. Pelarutan tersebut akan bertambah kuat apabila air pelarut mengandung dioksida karbon yang berasal dari udara maupun dari sisa-sisa tumbuhan yang telah lapuk. Hal inilah yang terjadi pada perbukitan karst di Nagari Paru, pada dinding batuan ditemukan celah yang memiliki alur.

\section{Hidrologi}

Berdasarkan hasil penelitian di atas mengatakan bahwa suhu udara Nagari Paru berkisar antara $26^{\circ} \mathrm{C}-33^{\circ} \mathrm{C}$. Curah hujan rata-rata Nagari Paru adalah 192 $\mathrm{mm} /$ tahun, curah hujan ini tergolong tinggi, hal ini disebabkan oleh pengaruh iklim tropis. Disamping Nagari Paru terletak pada iklim tropis, curah hujan yang tinggi juga disebabkan karena masih bagusnya hutan yang ada di Nagari Paru. Asdak (2007) mengatakan wilayah yang didominasi hutan atau vegetasi berkayu mempunyai angka curah hujan lebih besar dibanding dengan wilayah yang didominasi oleh padang rumput atau vegetasi semak belukar.

Asdak (2007) mengatakan bahwa keberadaan hutan hujan tropis adalah sebagai konsekuensi adanya curah hujan yang tinggi di daerah tropis. Hutan yang dijaga masyarakat Nagari Paru mempunyai humbungan timbal balik dengan curah hujan yang ada. Apabila masyarakat tidak menjaga hutan maka kekeringan akan melanda Nagari Paru. Rimbo Larangan yang didirikan oleh masyarakat Nagari Paru merupakan salah satu cara masyarakat dalam menjaga hutan. Kondisi hutan yang baik akan berpengaruh yang positif terhadap kondisi hidrologi sekitar. Salah cara untuk menjaga kondisi hidrologi suatu daeraha adalah dengan cara mempertahankan hutan selalu asri.

Banyak dampak yang sangat dirasakan oleh masyaarakat Nagari Paru setelah adanya Rimbo Larangan terutama dalam sistem pengairan sawah. Sekarang masyarakat bisa mengolah sawah mereka sesuka hati tanpa mengandalkan air hujan. Masyarakat mengandal sumber mata air yang berasal dari Rimbo Larangan. Air yang berasal dari Rimbo Larangan disamping dipergunakan untuk irigasi air sawah juga digunakan untuk sumber air minum dan keperluan rumah tangga lainnya. 
Cara masyarakat memanfaatkan air yang berasal dari Rimbo Larangan yaitu dengan cara membuat bak penampungan. Bak penampungan ini kemudian disambung dengan pipa untuk menyalurkan air ke rumah masyarakat. Sehingga masyarakat tidak lagi susah mengambil air ke sumur. Bak penampungan ini dibangun di bawah Rimbo Larangan Bukik Mandiangin. Selain untuk keperluan rumah tangga, juga di pergunakan untuk irigasi sawah. Sedangkan air yang berasal dari Rimbo Larangan Sungai Durian hanya dimanfaatkan untuk mengairi air swah. Hal ini dilakukan karena permukiman masyarakat sangat jauh dari Rimbo Larangan Sungai durian.

\section{Pemanfaatan Lahan di Sekitar Rimbo Larangan}

Menurut Ritoharjo (2013) penggunaan lahan merupakan usaha manusia memanfaatkan lingkunag alamnya untuk memenuhi kebutuhan-kebutuhan tertentu dalam kehidupan dan keberhasilannya. Penggunaan lahan bukan saja permukaan bumi yang berupa darat namun juga berupa perairan laut. Penggunaan lahan pada umumnya digunakan untuk mengacu pemanfaatan lahan masa kini, karena aktivitas manusia bersifat dinamis, sehingga perhatian kajian sering kali diarahkan pada perubahan-perubahan penggunaan lahan (baik secara kualitatif maupun kuantitatif) atau segala sesuatu yang berpengaruh terhadap lahan.

Berdasarkan hasil penelitian dilapangan dan analisis peta dengan GIS, penggunaan lahan di Nagari Paru dibedakan atas permukiman, sawah, kebun campuran dan hutan. Sedangkan penggunaan lahan pada Rimbo Larangan dikelompokan menjadi atas dua yaitu hutan primer dan hutan sekunder. Jadi pada dasarnya penggunaan lahan pada Rimbo Larangan adalah hutan. Penggunaan lahan di Nagari Paru sudah bisa dikatakan memenuhi acuan dari pemerintah lahan yang datar dan kering dipergunakan untuk lahan permukiman, lahan yang agak landai dan berair dipergunakan untuk sawah. Sedangkan daerah yang tidak mendapat irigasi dipergunakan untuk kebun dan lahan yang lerengnya terjal yang memungkinakan terjadinya longsor dipergunakan masyarakat sebagai hutan yang kemudian dijadikan Rimbo Larangan Nagari Paru. Untuk lebih jelasnya bisa dilihat pada peta pemanfaatan lahan di sekitar Rimbo Larangan dibawah ini: 


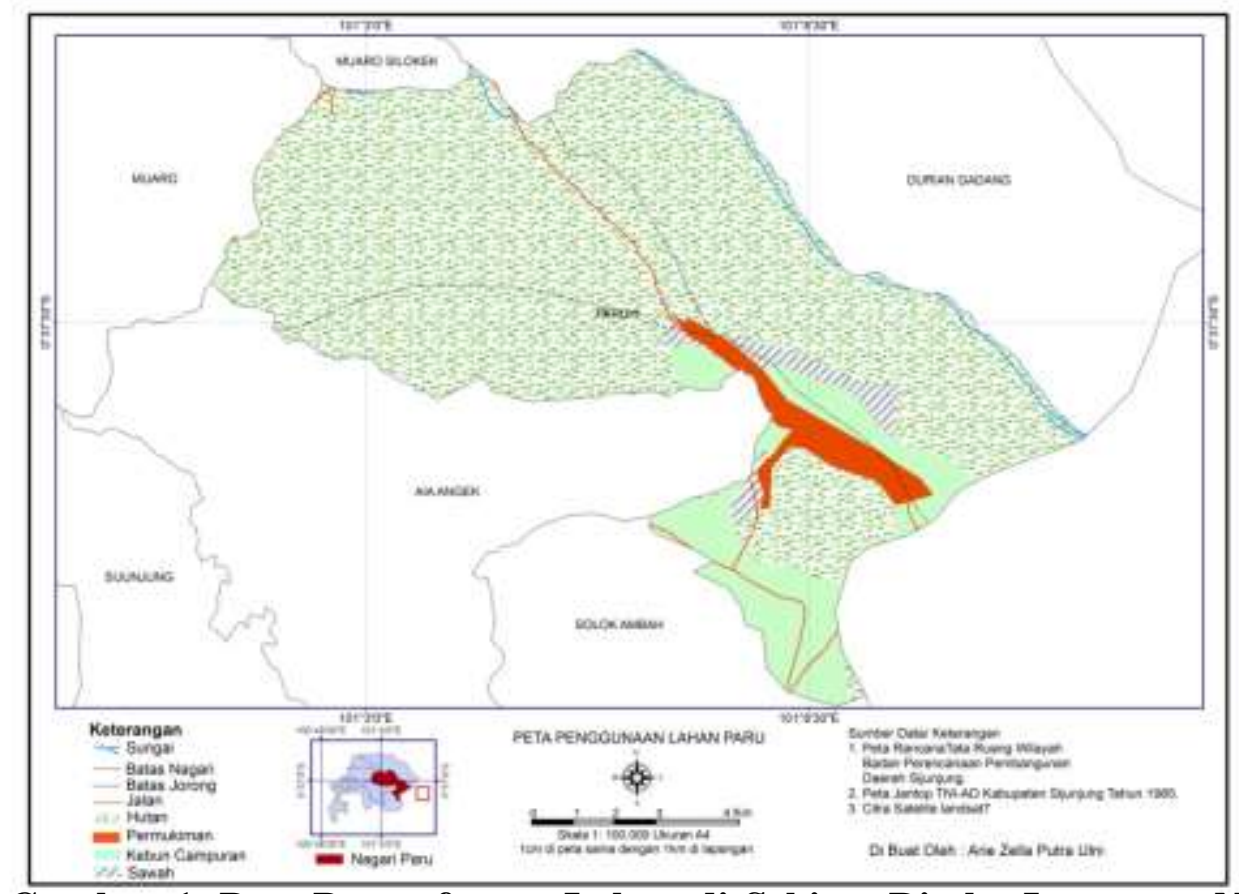

Gambar 1. Peta Pemanfaatan Lahan di Sekitar Rimbo Larangan Nagari Paru

Kerapatan perkampungan di dataran aluvial, berhubungan erat dengan kemiringan rendah (topografi datar) dan sifat kesuburan tanah dari bahan vulkanik muda. Kerapatan mulai berkurang ke arah pegunungan, sesuai dengan makin terjalnya lereng (Ritaharjo, 2013). Berdasarkan hal inilah penggunaan lahan untuk permukiman di Nagari Paru sudah sesuai dengan ketentuan yang ada.

Daerah persawahan yang baik yaitu mempunyai irigasi teratur dan kesuburan tanah yang tinggi. Semakin jauh dari irigasi dan sumber mata air memngakibatkan kualitas lahan persawhan semakin menurun dan kecendrungan untuk gagal panen semakin besar (Ritaharjo, 2013). Sawah yang terdapat di Nagari Paru terletak di kaki perbukitan yang ditumbuhi dengan semua jenis tanaman dan mempunyai mata air yang selalu mengalir setiap tahun. Untuk menjaga mata air yang ada di Nagari Paru, masyarakat menjadikan hutan sebagai Rimbo Larangan.

Perkebunan merupakan salah satu bentuk penggunaan lahan kering untuk pertanian. Karakteristik usaha pertanian lahan kering terdapat di daerah yang berpenduduk jarang, daerah ini tidak mendapat air irigasi dan sebagainya. Jenis tanaman untuk daerah ini adalah karet, kelapa dan sebagainya (Ritaharjo, 2013). Apabila dilihat di Nagari Paru tanaman yang ditanam pada kebun adalah karet. 


\section{KESIMPULAN}

Berdasarkan hasil pengamatan, pengukuran dan pengolahan data di lapangan. Karakteristik fisik lahan Nagari Paru sangat bervariasi, kemiringan lereng di Nagari Paru dapat dibedakan atas tiga yaitu datar, landai dan agak curam. Bentuk lahan Nagari Paru tebagi atas tiga bagian yatu dataran aluvial, tanggul alam dan perbukitan karst. Kondisi hidrologi sangat erta kaitannya denga DAS, sungai yang mengalir di Nagari paru adalah Batang Paru, yang mana sumber airnya berasal dari mata air yang terdapat di dalam Rimbo Larangan. Pemanfaatan lahan di sekitar Rimbo Larangan

\section{DAFTAR PUSTAKA}

Asdak, Chay. 2007. Hidrologi dan Pengelolaan Daerah Aliran Sungai. Gadjah Mada University Press. Yogyakarta.

Hardjowigeno, Sarwono. 2011. Evaluasi Kesesuaian Lahan dan Perencanaan Tata Guna Lahan. Yogyakarta: UGM Press.

Ritoharjo, Su. 2013. Penggunaan dan Tata Guna Lahan. Yogyakarta: Ombak.

SK Wali Nagari Paru Nomor 188.47/05/Kpts-WN-2003 ditetapkan KPPH (Kelompok Petani Peduli Hutan). 